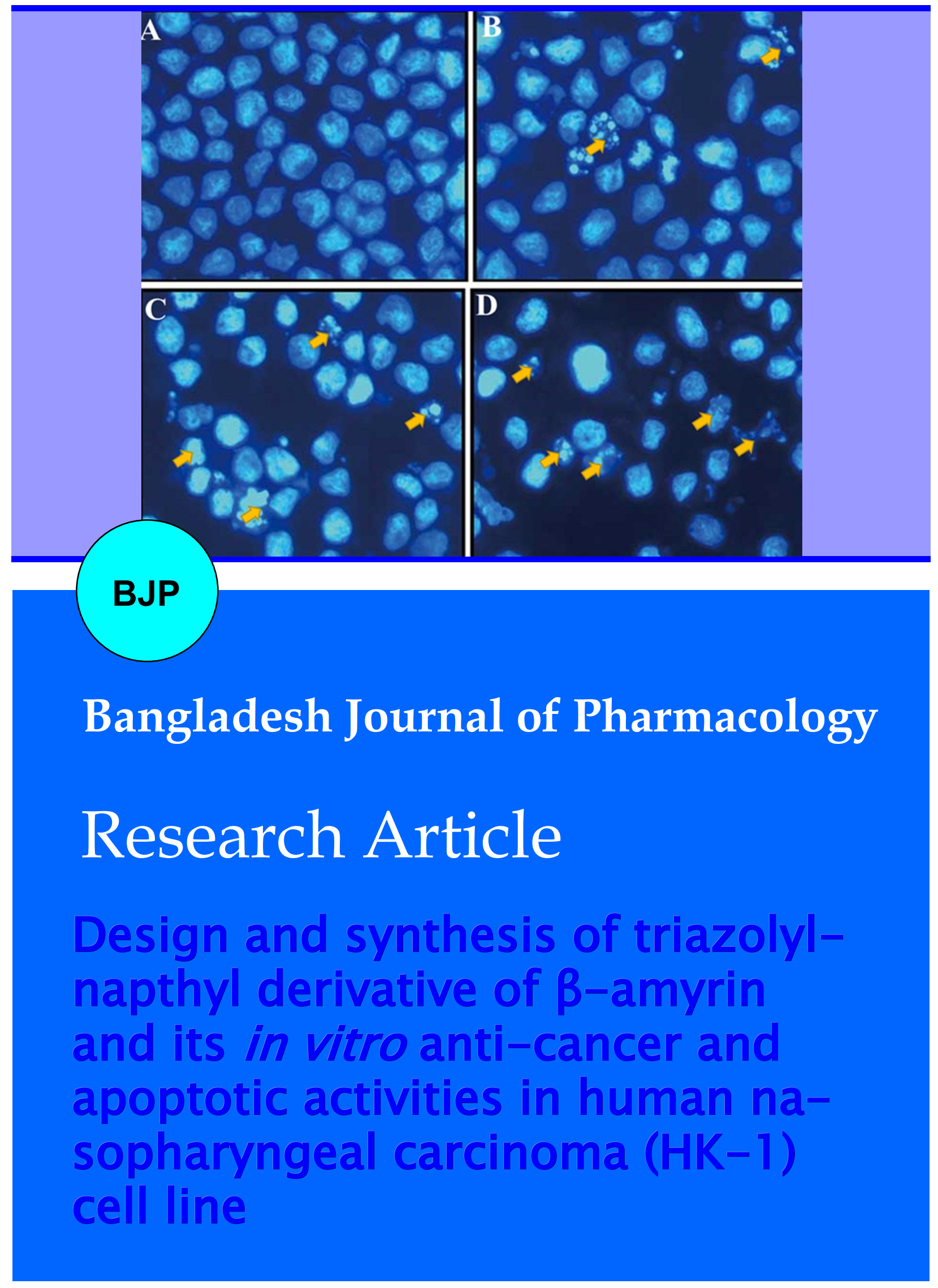


Abstracted/indexed in Academic Search Complete, Asia Journals Online, Bangladesh Journals Online, Biological Abstracts, BIOSIS Previews, CAB Abstracts, Current Abstracts, Directory of Open Access Journals, EMBASE/Excerpta Medica, Google Scholar, HINARI (WHO), International Pharmaceutical Abstracts, Open J-gate, Science Citation Index Expanded, SCOPUS and Social Sciences Citation Index;

ISSN: $1991-0088$

\title{
Design and synthesis of triazolyl-napthyl derivative of $\beta$-amyrin and its in vitro anti-cancer and apoptotic activities in human nasopharyngeal carcinoma (HK-1) cell line
}

\author{
Zhen Li1,2, Hong-Zhou Ge3, Yong-Gang Xie4 and Shi Li1 \\ ${ }^{1}$ Department of Otorhinolaryngology, The Second Hospital of Shandong University, Jinan, Shandong, P. R. China; \\ ${ }^{2}$ Department of Otorhinolaryngology, Yantaishan Hospital Affiliated to Medical College of Taishan, Yantai, P. R. China; \\ ${ }^{3}$ Department of Otorhinolaryngology, Laixi Renmin Hospital, Shandong, P. R. China; ${ }^{4}$ Department of Anesthesiology, \\ Yuhuangding Hospital Affiliated to Medical College of Qingdao University, Yantai 264 000, P. R. China.
}

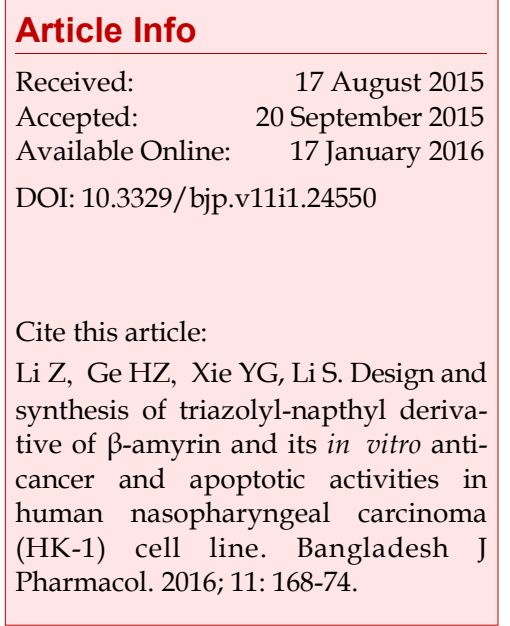

\begin{abstract}
The purpose of this research work was to design and synthesize triazolylnapthyl derivative of $\beta$-amyrin (TNB) using click chemistry approach. The cytotoxic activity of TNB was evaluated against HK-1 human nasopharyngeal carcinoma cells using MTT cell viability assay. Fluorescence microscopy indicated cellular morphological changes induced by TNB. Flow cytometry was involved to demonstrate the effect of this compound on cell cycle and apoptosis. The results revealed that TNB inhibited in vitro cancer cell growth in dose- and time-dependent manner. The $\mathrm{IC}_{50}$ values of TNB at 24 and 48 hours time intervals were found to be 47.2 and $32.5 \mu \mathrm{M}$ respectively. TNBtreated cells exhibited significant dense staining fragmentation called apoptotic bodies, which inferred an early apoptotic event. DNA ladder was more apparent with the increasing the TNB dose. However, no DNA fragments were observed in the control groups. TNB also induced sub-G1 cell cycle arrest and increased fraction of $\mathrm{HK}-1$ apoptotic cells.
\end{abstract}

\section{Introduction}

Nasopharyngeal carcinoma is fairly uncommon in maximum part of the world. Approximately 7 in every 1 million people in America were diagnosed in 2012 (American Cancer Society). Nevertheless, it is more common in parts of Asia, predominantly in the Southern China. Nasopharyngeal carcinoma occurs in children and adults but is most common in males. In comparison to other types of cancers, nasopharyngeal carcinoma is considered very rare but it has been affecting certain ethnic groups in China for decades. In addition to ethnic background, it has been described that nasopharyngeal carcinoma also originates due to dietary habits including high alcohol consumption and salted food (Ning et al., 1990).
Nasopharyngeal carcinoma can be treated by surgery, chemotherapy, radiotherapy or their combination. Even though there are conventional therapies, the serious side effects and toxicities are intolerable to patients (Suárez et al., 2010).

Several compounds isolated from plants have displayed anticancer effect against nasopharyngeal carcinoma (Lui et al., 2009; Lin et al., 2010; Kuo et al., 2012). Conventional anticancer drugs, paclitaxel and cisplatin have been used which worked synergistically with cetuximab to enhance the antitumor effect in nasopharyngeal carcinoma which down-regulates the over-expression of epidermal growth factor receptor (EGFR) (Sung et al., 2005). The aim of the present study was to evaluate the anti-cancer and apoptotic effects of 
the $\beta$-amyrin and its triazolyl-napthyl derivative in HK1 nasopharyngeal carcinoma cells along with evaluating further the mode of action by studying its effect on cellular morphology, cell cycle arrest and DNA fragmentation.

\section{Materials and Methods}

\section{Chemicals and reagents}

$\beta$-Amyrin ( $\geq 98 \%$ purity) was purchased from Sigma Chemical Company (USA). Growth medium (MEM/ RPMI), fetal calf serum, trypsin, penicillin, streptomycin, DMSO, RNase, RIPA Buffer, SDS, MTT dye, propidium iodide, Hoechst 33258 were obtained from Hangzhou Sijiqing Biological Products Co. Ltd, China. All other chemicals and solvents used were of the highest purity grade.

\section{Chemical synthesis of triazolyl-napthyl derivative of $\beta$ -amyrin (TNB) using click chemistry approach}

To a solution of $\beta$-amyrin (1, $500 \mathrm{mg})$ in THF was added cesium carbonate $(600 \mathrm{mg}$ ) and propargyl bromide (675 $\mathrm{mg}$ ) and the reaction mixture was stirred at room temperature for 3 hours. The crude product isolated was further subjected to column chromatography to give pure compound (propargylated derivative of $\beta$ amyrin) $(2,300 \mathrm{mg})$. To a solution of compound $(2,300$ $\mathrm{mg})$ in $\mathrm{tBuOH}-\mathrm{H}_{2} \mathrm{O}(2: 1,10 \mathrm{~mL})$ was added sodium ascorbate $(3.5 \mathrm{mg})$ and $\mathrm{CuSO}_{4}(1.5 \mathrm{mg})$. To this mixture, napthyl azide (2 equivalents) was added and the reaction mixture was sonicated at $45^{\circ} \mathrm{C}$ till its completion was monitored by TLC. After completion, the reaction mixture was diluted with water and extracted with ethyl acetate. The organic layer was dried over sodium sulfate and purified by column chromatography to give pure compound (3) which is the triazolyl-napthyl derivative of $\beta$-amyrin (Scheme 1 ).

\section{Cell lines, growth medium and treatment conditions}

Human nasopharyngeal carcinoma (HK-1) cell line was procured from Shanghai Institute of Cell Resource Center of Life Science (China). Cells were grown in Minimum Essential Medium (MEM) and RPMI supplemented with $10 \%$ FCS and 1\% penicillin. Cells were cultured in $\mathrm{CO}_{2}$ incubator (New Brunswick, Galaxy $170 \mathrm{R}$, eppendroff) with an internal atmosphere of $95 \%$ air and $5 \% \mathrm{CO}_{2}$ gas and the cell lines were maintained at $37^{\circ} \mathrm{C}$. The media was stored at low temperature $\left(2-8^{\circ}\right.$ C) and the medium for cryopreservation contained $10 \%$ FCS and 5\% DMSO in growth medium.

\section{Cell viability testing by MTT assay}

The cytotoxic effects of TNB on the cell viability of HK1 human nasopharyngeal carcinoma cells was evaluated by MTT assay. HK-1 cell line was seeded in a 96well plate at $3 \times 10^{3}$ cells per well and then treated with $0,3,6,12,24,50$ and $100 \mu \mathrm{M}$ dose of TNB for 24 and 48 hours. The cell plates were then treated with MTT solution $(10 \mu \mathrm{L})$ in PBS for two hours. The formazan crystals then formed were dissolved in DMSO and the absorbance was measured on a microplate reader (FLUOstar Optima, BMG Labtech, Germany). Data were expressed as a percentage of control measured in

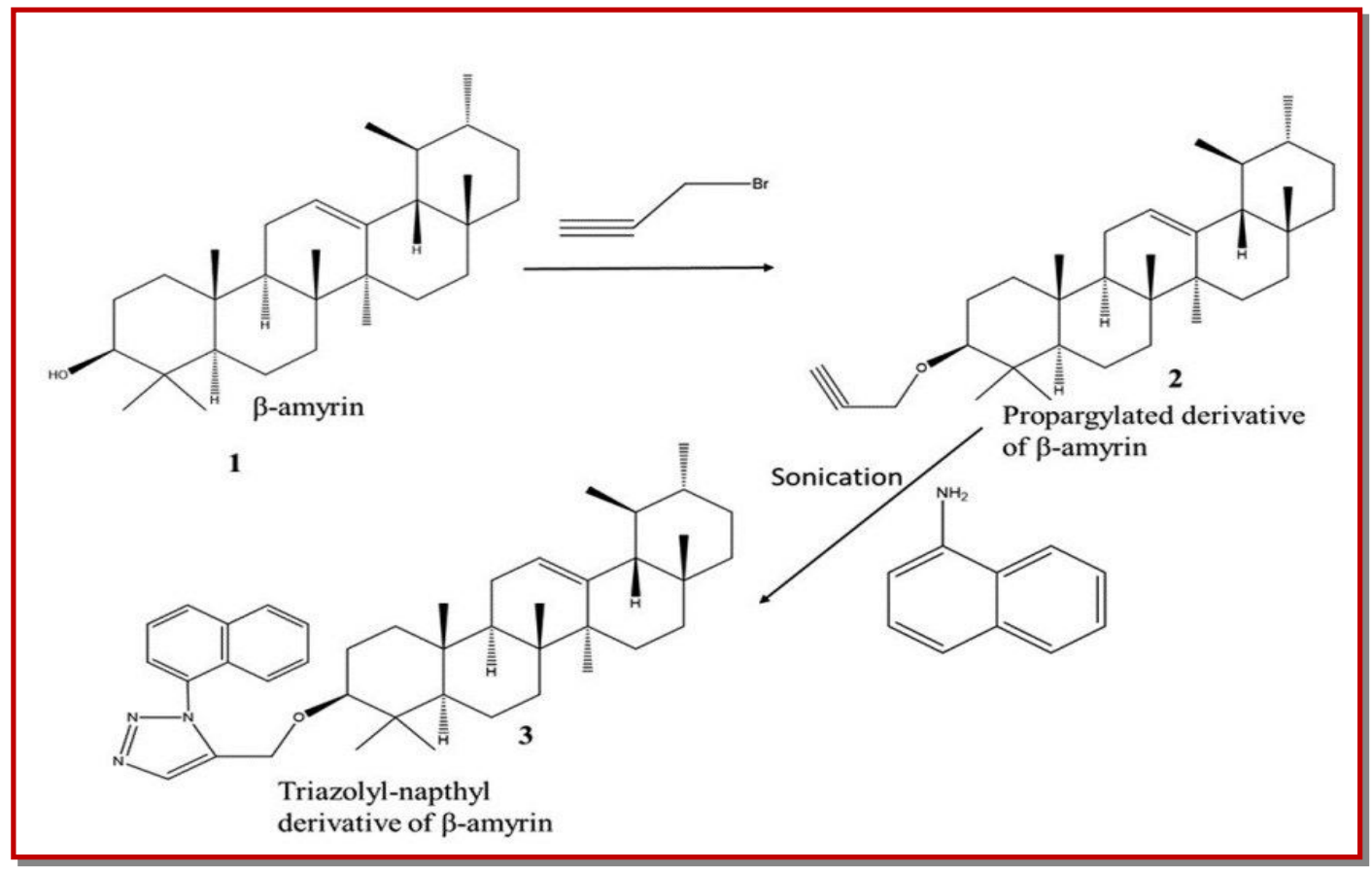

Scheme 1: Chemical synthesis of triazolyl-napthyl derivative of $\beta$-amyrin using click chemistry approach 
the absence of TNB compound.

\section{Fluorescence microscopic study}

HK-1 cells were seeded on a chamber slide (Thermo Scientific Nunc Lab Tek II) at a cell density of $3 \times 10^{5}$ cells per chamber. The cells were treated with $0,12,48$ and $100 \mu \mathrm{M}$ TNB for 48 hours. Afterward, $20 \mu \mathrm{g} / \mathrm{mL}$ of acridine orange and $20 \mu \mathrm{g} / \mathrm{mL}$ of propidium iodide were added to each chamber. It was then observed under Fluoview 1000 laser scanning confocal microscope (Olympus IX 81 motorized inverted microsope).

\section{DNA fragmentation analysis after TNB treatment}

The HK- 1 cells $\left(3 \times 10^{5}\right.$ cells/dish) were plated in $6-\mathrm{cm}$ dish and then subjected to the treatment of various concentrations $(0,12,48$ and $100 \mu \mathrm{M})$ of the TNB for 48 hours. After drug treatment, the cells were washed with ice-cold PBS and resuspended in lysis buffer $(25 \mathrm{mM}$ Tris- $\mathrm{HCl}$, pH 7.4, 5 mM EDTA and 0.6\% SDS) with 1.0 $\mathrm{mg} / \mathrm{mL}$ RNase A for $20 \mathrm{~min}$ at $50^{\circ} \mathrm{C}$. Then proteinase $\mathrm{K}$ was added and the cells were incubated overnight. Separation of DNA was done using $2 \%$ agarose gel and detected under UV light after staining with ethidium bromide (ETBR).

\section{Effect of TNB on cell cycle phase distribution}

Cell cycle was analyzed by FACSC alibur instrument (BD Biosciences, USA) equipped with Cell Quest 3.3 software. Briefly, HK-1 cells $\left(3 \times 10^{5}\right)$ cells were treated with various concentrations of $\operatorname{TNB}(0,12,48$ and 100 $\mu \mathrm{M})$ for 48 hours. After this, the cells were collected, washed with ice-cold PBS buffer, fixed with $70 \%$ alcohol at $4^{\circ} \mathrm{C}$ for 12 hours, and stained with propidium iodide in the presence of $1 \%$ RNAase $\mathrm{A}$ at $37^{\circ} \mathrm{C}$ for 30 min before analysis by flow cytometry.

\section{Annexin $V$ binding assay/Quantification of apoptotic cell death}

To establish and confirm cells undergoing apoptosis, we performed annexin $\mathrm{V}$ binding assay through flow cytometry. Briefly, HK-1 cancer cells were treated with the $\operatorname{TNB}(0,12,48$ and $100 \mu \mathrm{M})$ for 48 hours, and then treated and untreated cells were harvested by trypsinization. Harvested cells were then incubated in annexin V-FITC (25 ng/mL) and propidium iodide (25 $\mu \mathrm{g} / \mathrm{mL}$ ), at room temperature for $30 \mathrm{~min}$ in the dark, and analyzed using a FACS Calibur flow cytometer (BD Bioscience) taking a minimum 10,000 cells in each sample.

\section{Statistical analysis}

All data were derived from at least three independent experiments. The results were expressed as the mean \pm SD. Differences between groups were analyzed using the Student's t-test. $\mathrm{p}<0.05$ was considered statistically significant.

\section{Results}

\section{In vitro cytotoxic effect of TNB}

We evaluated in vitro inhibitory effect of TNB using the MTT viability assay against $\mathrm{HK}-1$ cells at indicated concentrations of $0,3,6,12,24,50$ and $100 \mu \mathrm{M}$ for 24 and 48 hours. The results revealed that TNB had potent cytotoxic effects on HK-1 nasopharyngeal cancer cells. It revealed both concentration-dependent as well as time-dependent growth inhibitory effects against these cells (Figure 1). The efficacy of the compound was evaluated at two different time intervals by calculating the $\mathrm{IC}_{50}$ values, which is the concentration that causes $50 \%$ growth inhibition. The $\mathrm{IC}_{50}$ values of $\mathrm{TNB}$ at 24 and 48 hours time intervals were found to be 47.2 and $32.5 \mu \mathrm{M}$ respectively.

Fluorescence microscopic study of TNB-induced cellular morphological changes

In the case of fluorescence microscopy, HK-1 cells were stained and evaluated for nuclear shape using a fluorescence microscope with Hoechst 33258 staining (Figure 2A-D). The results revealed that TNB-treated cells showed considerable chromatin condensation or dense staining fragmentation called apoptotic bodies, which inferred an early apoptotic event. The presence of such apoptotic bodies was related to the TNB dose. HK-1 cells underwent the morphologic changes typical of apoptosis after treatment with the compound. Uniformly spherical HK-1 cells with normal morphology were observed in untreated cultures, whereas chromatin condensation, chromosomal DNA cleavage were observed when HK-1 cells were treated with TNB at different concentrations.

\section{Effect of TNB on DNA fragmentation}

Besides the morphological changes of apoptosis in TNB -treated HK-1 cells, DNA fragmentation was also studied by evaluation of the formation of DNA ladder. As shown in Figure 3, DNA ladder appeared to be more evident with the increasing TNB concentration, however, no DNA fragments were observed in the control groups (Figure 3; $0 \mu \mathrm{M}$ ). However, 12, 48 and $100 \mu \mathrm{M}$ doses of the compound after 48 hours exposure led to a considerable upsurge in DNA fragmentation (Figure 3; right panel). The DNA fragmentation is a symbol of apoptosis, further confirming that the TNB compound induced cell death through apoptosis.

\section{Effect of TNB on cell cycle phase distribution}

Apoptosis and cell cycle are strictly related biochemical processes, and any interference in cell cycle progression may eventually lead to apoptotic cell death. DNA content in cells was detected by propidium iodide staining and flow cytometry. In order to elucidate the mechanistic pathway of the growth inhibitory effect 


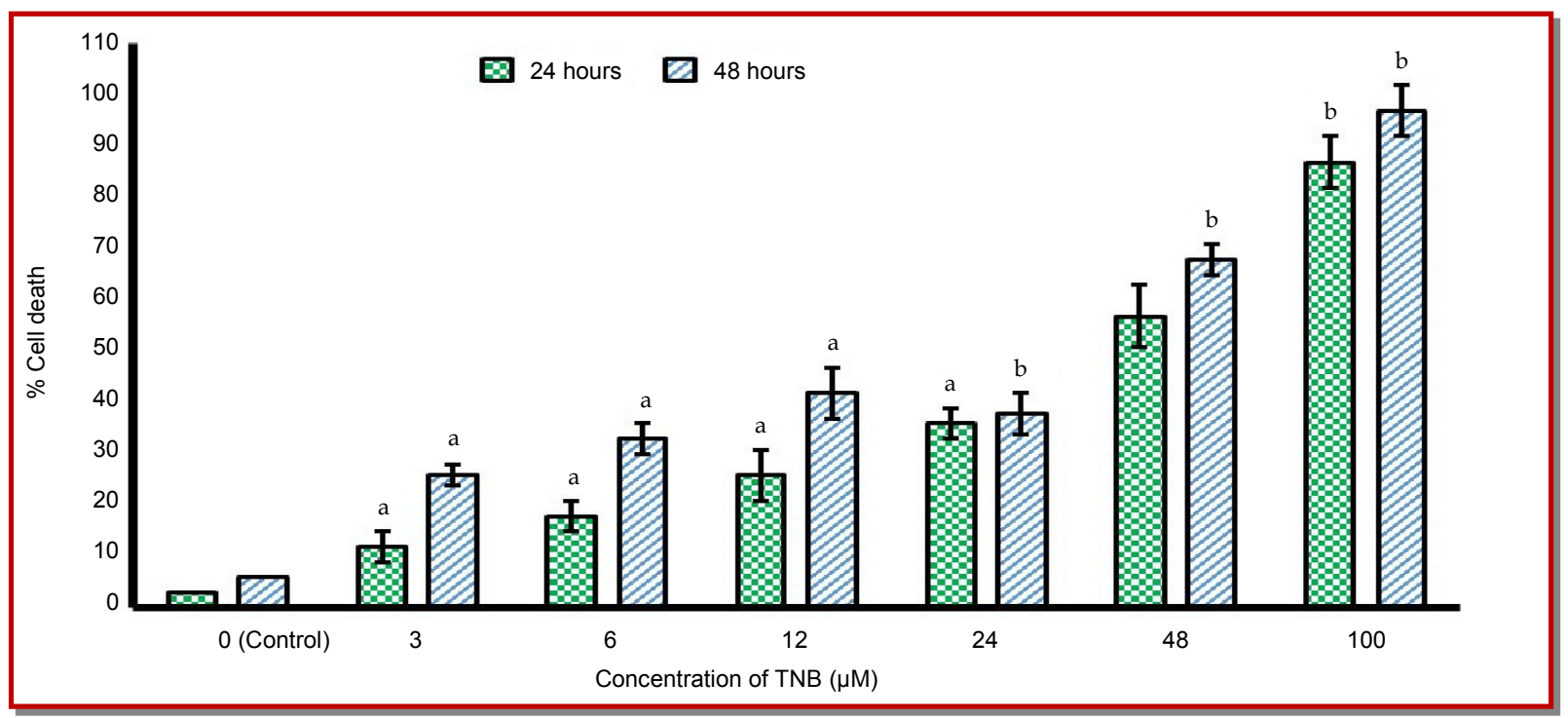

Figure 1: Cytotoxic effect of triazolyl-napthyl derivative of $\beta$-amyrin (TNB) in human nasopharyngeal carcinoma cells (HK-1). Data are shown as the mean \pm SD of three independent experiments. ${ }^{a} \mathrm{p}<0.05$, ${ }^{b} \mathrm{p}<0.01$, vs $0 \mu \mathrm{M}$ (control)

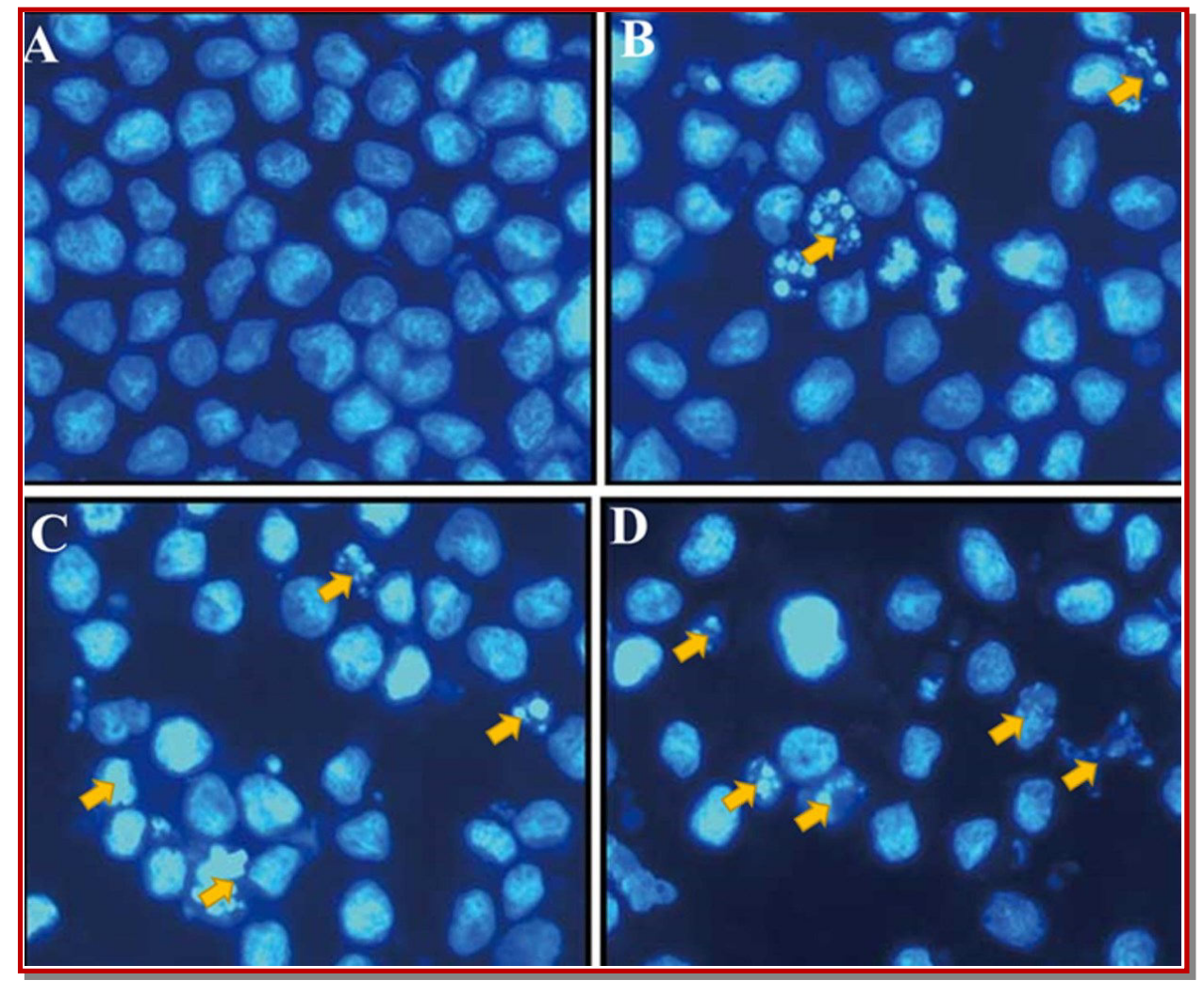

Figure 2: Effect of TNB on the nuclear morphology of HK-1 cancer cells using Hoechst 33258 staining at actual magnification 200x. HK-1 cells were treated without (A) and with TNB $12 \mu \mathrm{M}(\mathrm{B}), 48 \mu \mathrm{M}(\mathrm{C})$, and $100 \mu \mathrm{M}$ (D) for 48 hours. Colored arrows represent apoptotic cells exhibiting chromatin condensation and nuclear fragmentation

exerted by TNB in HK-1 cancer cells, flow cytometry analysis was carried out to ascertain whether TNB induces cell cycle arrest in this cell line. The results revealed that TNB induces sub-G1 cell cycle arrest and increases the fraction of apoptotic cells in HK-1 cells in a dose-dependent manner (Figure 4). At the same time, the fraction of G0/G1 cells decreased with the increase in the dose of TNB. The percentage of cells in S and G2/ $M$ phase more or less remained unaffected.

\section{TNB induced both early and late apoptosis}

Annexin V/PI double staining was used to detect 


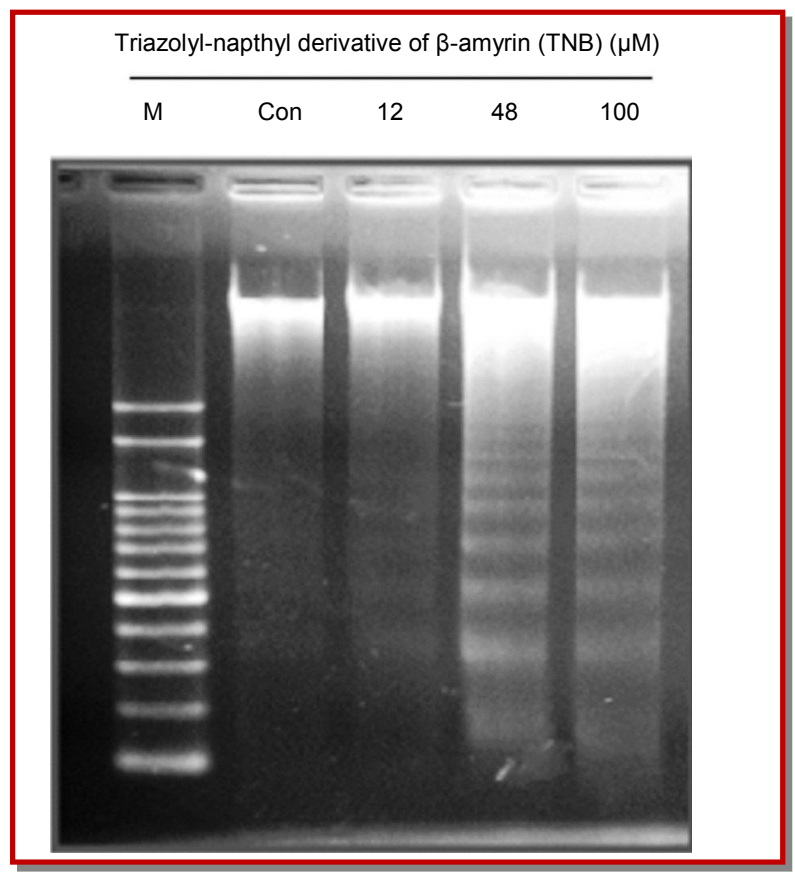

Figure 3: TNB induces DNA fragmentation in human nasopharyngeal cancer cells (HK-1). The cells were treated with 0 , 12,48 and $100 \mu \mathrm{M}$ of the compound for 48 hours. Cells from each sample were harvested for DNA gel electrophoresis as described in Materials and Methods

apoptosis in the human nasopharyngeal cancer cells (HK-1) (Figure 5A-D). HK-1 cells were treated with different concentration $(0,12,48$ and $100 \mu \mathrm{M})$ of TNB for 48 hours. TNB induced both early and late apoptosis in a concentration-dependent manner (Figure 5B-D) as compared to the untreated control cells (Figure 5A). The different quadrants Q1, Q2, Q3 and Q4 represent necrotic cells, late apoptotic cells, viable cells and early apoptotic cell population respectively. Percentage of apoptotic cells increases from 5.6\% in control cells (A), to $29.3 \%, 37.1 \%$ and $45.2 \%$ in $12 \mu \mathrm{M}(\mathrm{B}), 48 \mu \mathrm{M}(\mathrm{C})$ and $100 \mu \mathrm{m}$ (D) TNB-treated cells respectively.

\section{Discussion}

In the present study, it was reported that triazolylnapthyl derivative of $\beta$-amyrin (TNB) exhibited potent antitumor activity in human nasopharyngeal cancer cells (HK-1) by inducing early and late apoptosis, cell cycle arrest in sub-G1 phase and DNA fragmentation. Cell viability assay using MTT showed that TNB inhibited in vitro cancer cell growth in a dosedependent and time-dependent manner. The $\mathrm{IC}_{50}$ values of TNB at 24 and 48 hours time intervals were found to be 47.2 and $32.5 \mu \mathrm{M}$ respectively. Fluorescence microscopy studies revealed that TNB-treated cells exhibited significant chromatin condensation or dense staining fragmentation called apoptotic bodies, which inferred an early apoptotic event. Homogenously spherical HK-1 cells with normal morphology were seen in untreated cells, whereas chromatin condensation and chromosomal DNA cleavage were observed when HK-1 cells were treated with TNB at different concentrations. Further, gel electrophoresis indicated that DNA ladder seemed to be more apparent with the increasing the TNB dose, however, no DNA fragments were observed in the control groups. 12, 48 and $100 \mu \mathrm{M}$ doses of the compound after 48 hours exposure led to a considerable upsurge in DNA fragmentation. Flow cytometry studies indicated that TNB induces sub-G1 cell cycle arrest and increases the

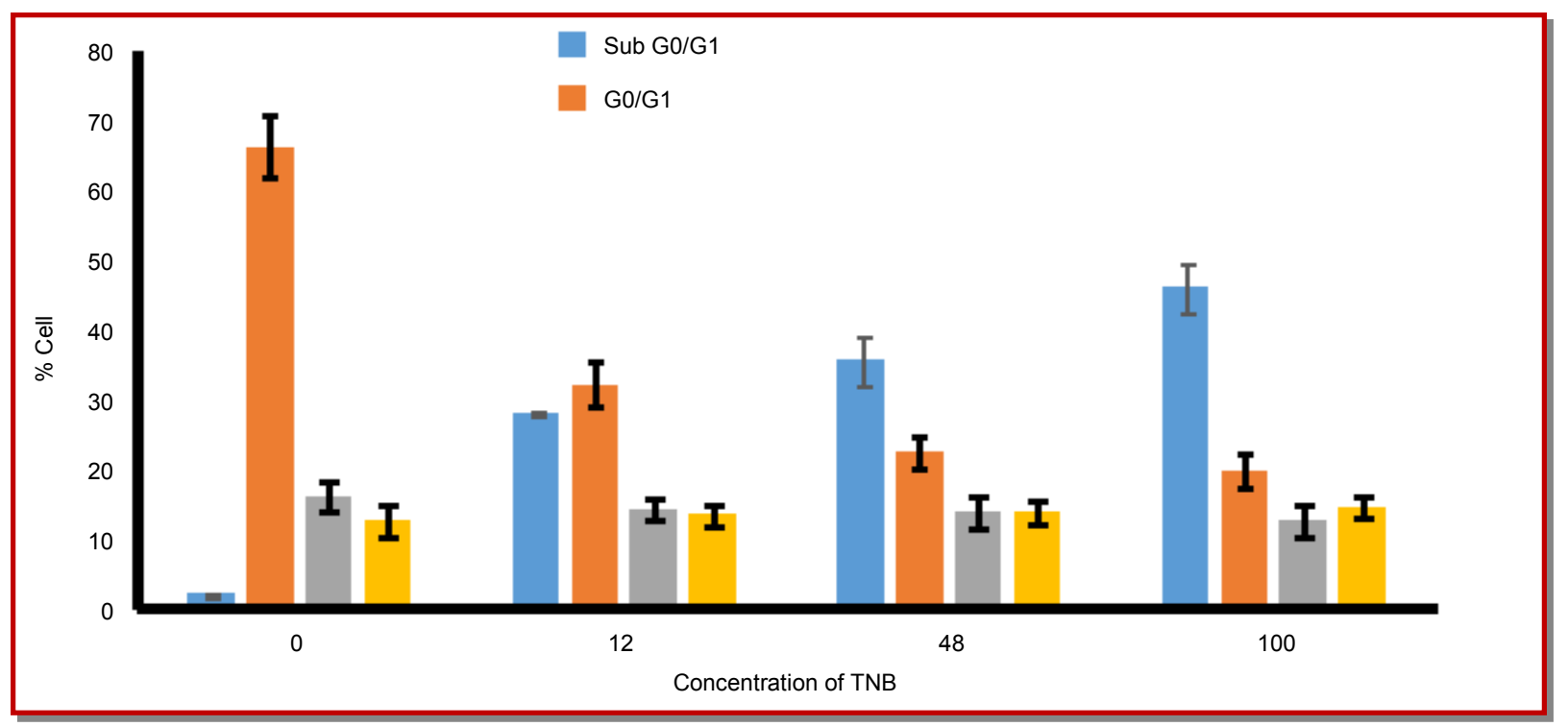

Figure 4: Effect of TNB on the cell cycle analysis of the HK-1 nasopharyngeal carcinoma cells. The cells were treated with $0,12,48$ and $100 \mu \mathrm{M}$ of the compound for 48 hours and then analyzed by flow cytometry. Note the percentage of sub-G0/G1 (apoptotic cells) cells increases with increase in dose of TNB 


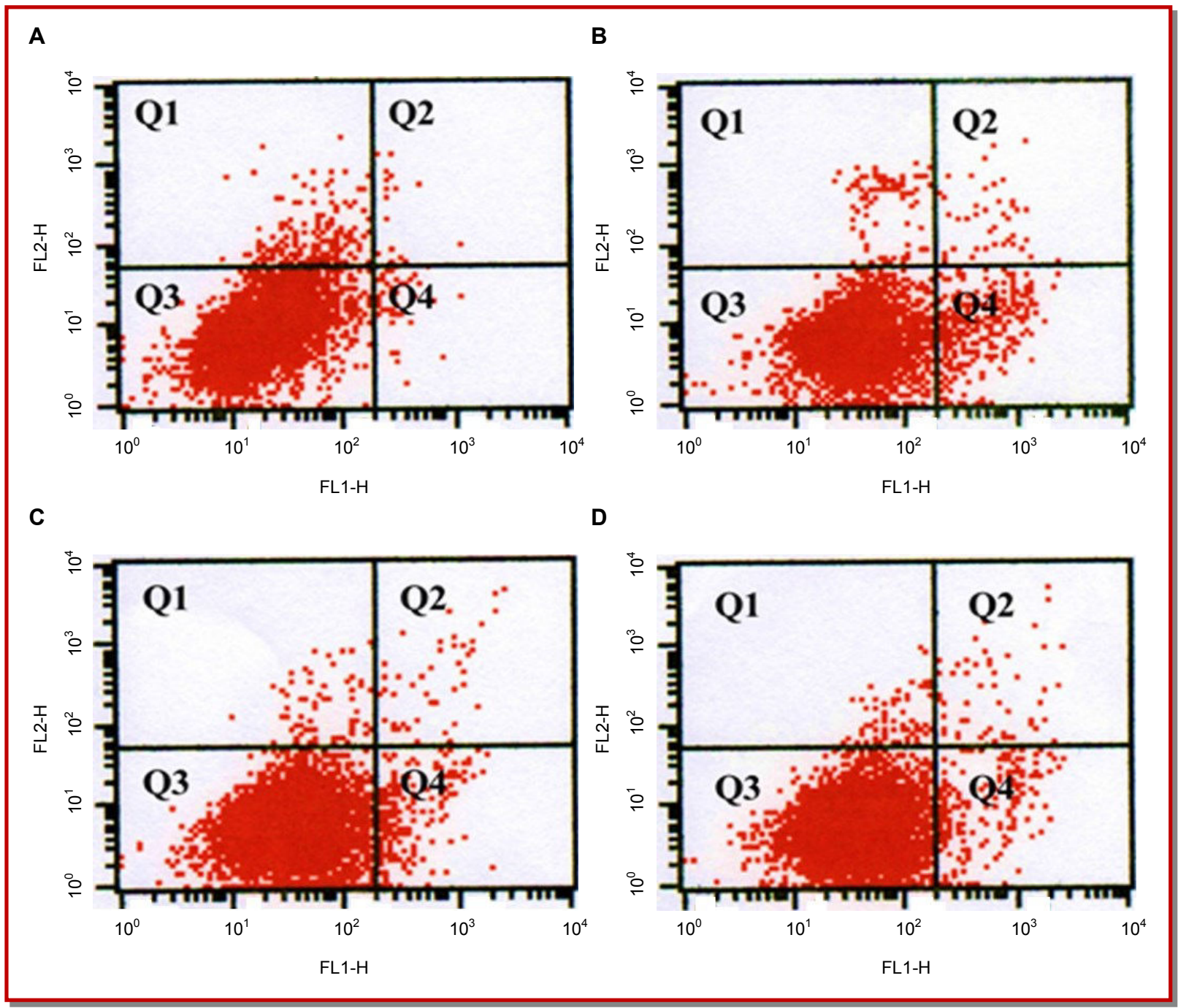

Figure 5: Quantification of TNB-induced apoptosis in human nasopharyngeal cancer cells (HK-1). The cells were subjected to different doses of TNB $(0,12,48$ and $100 \mu \mathrm{M})$ for 48 hours and analyzed by flow cytometry with annexin V-FITC/PI staining. The different quadrants Q1, Q2, Q3 and Q4 represent necrotic cells, late apoptotic cells, viable cells and early apoptotic cell population respectively. Percentage of apoptotic cells increases from 5.6\% in control cells (A), to $29.3 \%, 37.1 \%$ and $45.2 \%$ in $12 \mu \mathrm{M}$ (B), $48 \mu \mathrm{M}$ (C) and $100 \mu \mathrm{m}(\mathrm{D})$ TNB-treated cells respectively

fraction of HK-1 apoptotic cells in a dose-dependent manner. However, the percentage of G0/G1 cells diminished with the increase in the dose of TNB. TNB induced both early and late apoptosis in a concentration -dependent manner as compared to the untreated control cells.

$\beta$-amyrin is a pentacyclic triterpenoid synthesized by a number of plants. This compound is often found in plant extracts along with its isomer a-amyrin differing in the placement of one methylene group (C-19 and C20 respectively). Literature survey revealed that no such research work has been reported on triazolyl-napthyl derivative of $\beta$-amyrin (TNB) so far. However, ester derivatives of amyrin have been reported to induce apoptotic cell death in HL-60 leukemia cells. This study also reported the effect of these ester derivatives on cellular morphology, DNA fragmentation, cell cycle arrest, externalization of phosphatidylserine and activation of caspases 3/7 (Barros et al., 2011). It has also been reported that $\alpha$ - and $\beta$-amyrin isomers protects the liver against acetaminophen-induced injuries and ameliorates L-arginine-induced acute pancreatitis. a-Amyrin esters have also been reported to show substantial anti-inflammatory activity (Oliveira et al., 2005; Melo et al., 2010; Akihisa et al., 2010). However, our study focused on triazolyl derivatives of betaamyrin rather than alpha-amyrin. Further, our study focused on a different cancer cell line namely nasopharyngeal carcinoma cell line. In literature we could not find reports on the anti-cancer activity of either alpha-amyrin or beta-amyrin or their derivatives against nasopharyngeal cancer cells and as such this report is the first such report on this cell line. 


\section{Conclusion}

TNB synthesized by using click chemistry approach, inhibit nasopharyngeal cancer cell (HK-1 cell line) growth by inducing apoptosis, chromatin condensation, DNA fragmentation and sub-G1 cell cycle arrest.

\section{Conflict of Interest}

The authors declare that there is no conflict of interest to reveal.

\section{References}

Akihisa T, Kojima N, Kikuchi T, Yasukawa K, Tokuda H, T Masters E, Manosroi A, Manosroi J. Anti-inflammatory and chemopreventive effects of triterpene cinnamates and acetates from shea fat. J Oleo Sci. 2010; 59: 273-80.

Barros FW, Bandeira PN, Lima DJ, Meira AS, de Farias SS, Albuquerque MR, dos Santos HS, Lemos TL, de Morais MO, Costa-Lotufo LV, Pessoa Cdo Ó. Amyrin esters induce cell death by apoptosis in HL-60 leukemia cells. Bioorg Med Chem. 2011; 19: 1268-76.

Kuo CL, Wu SY, Ip SW, Wu PP, Yu CS, Yang JS, Chen PY, Wu $\mathrm{SH}$, Chung JG. Apoptotic death in curcumin-treated NPCTW 076 human nasopharyngeal carcinoma cells is mediated through ROS, mitochondrial depolarization and caspase-3dependent signalling responses. Int J Oncol. 2012; 39: 319-28.

Lin ML, Lu YC, Chung JG, Li YC, Wang SG, N G SH, Wu CY, $\mathrm{Su}$ HL, Chen SS. Aloe-emodin induces apoptosis of human nasopharyngeal carcinoma cells via caspase-8-mediated activation of the mitochondrial death pathway. Cancer Lett. 2010; 291: 46-58.

Lui VW, Yau DM, Wong EY, Ng YK, Lau CP, Ho Y, Chan JP, Hong B, Ho K, Cheung CS, Tsang CM, Tsao SW, Chan AT. Cucurbitacin I elicits anoikis-sensitization, inhibits cellular invasion and in vivo tumor formation ability of nasopharyngeal carcinoma cells. Carcinogenesis 2009; 30: 208594.

Melo CM, Carvalho KM, Neves JC, Morais TC, Rao VS, Santos FA, Brito GA, Chaves MH. Alpha, beta-amyrin, a natural triterpenoid ameliorates L-arginine-induced acute pancreatitis in rats. World J Gastroenterol. 2010; 16: 4272-80.

Ning JP, Yu MC, Wang QS, Henderson BE. Consumption of salted fish and other risk factors for nasopharyngeal carcinoma (NPC) in Tianjin, a low-risk region for NPC in the People's Republic of China. J Natl Cancer Inst. 1990; 82: 29196.

Oliveira FA, Chaves MH, Almeida FR, Lima RC Jr, Silva RM, Maia JL, Brito GA, Santos FA, Rao VS. Protective effect of alpha- and beta-amyrin, a triterpene mixture from Protium heptaphyllum (Aubl.) March. trunk wood resin, against acetaminophen-induced liver injury in mice. J Ethnopharmacol. 2005; 98: 103-08.

Suárez C, Rodrigo JP, Rinaldo A, Langendijk JA, Shaha AR, Ferlito A. Current treatment options for recurrent nasopharyngeal cancer. Eur Arc Otorhinolaryngol. 2010; 267: 1811-24.

Sung FL, Poon TC, Hui EP, Ma BB, Liong E, To KF, Huang DP, Chan AT. Antitumor effect and enhancement of cytotoxic drug activity by cetuximab in nasopharyngeal carcinoma cells. In vivo. 2005; 19: 237-45.

Author Info
Shi Li (Principal contact)
e-mail: zxcshili@hotmail.com
First two authors contributed equally 


\section{Your feedback about this paper}

1. Number of times you have read this paper 0

2. Quality of paper Click

3. Your comments

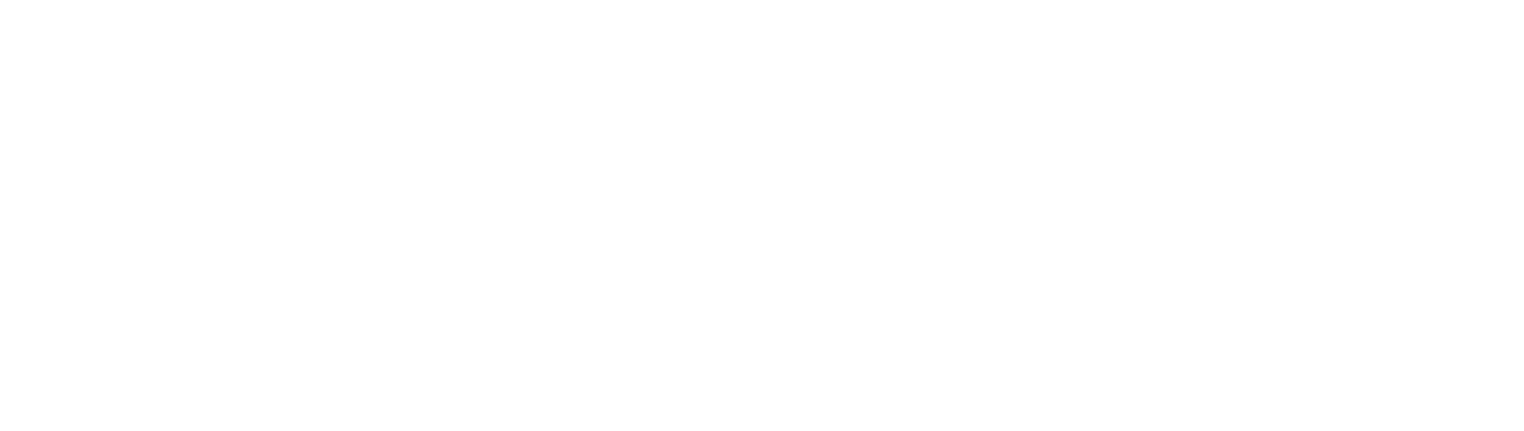

